\section{Amplification of Hsp90 Homologs from Plant- Parasitic Nematodes Using Degenerate Primers and Ramped Annealing PCR}

BioTechniques 29:1182-1186 (December 2000)

Procedures for using PCR to amplify novel members of gene families from genomic DNA frequently involve the use of degenerate primers. Of key importance is the ability to produce ample quantities of specific PCR product while minimizing or eliminating nonspecific side reactions. Primer design protocols and software are improving, but finding the optimal amplification conditions often involves a tremendous amount of time and expense. Degenerate PCR primers can be designed based on consecutive stretches of conserved amino acids. General criteria for guiding this process have been described $(5,8)$, and a number of standalone or Web-based computer programs exist to facilitate primer selection $(9,10)$. A comparison of sequences from closely related organisms, combined with knowledge of codon usage in the target organism, is enormously helpful. Selected homologous protein sequences are typically aligned with programs such as ClustalW (12). Stretches of consecutive amino acids that are identical in all of the aligned sequences are chosen for reverse translation, and the corresponding nucleotide sequences are used in the design of consensus or degenerate oligonucleotide primers. A direct alignment of nucleic acid sequences can be used if sufficient nucleotide sequence homology exists.

The use of degenerate rather than consensus primers in PCR increases the possibility of including a primer with exact complementarity to an unknown target DNA sequence. However, in highly degenerate primer pools (> 500-fold), the actual concentration of an exact match primer will be a very small fraction of the total added. Unfortunately, there are no hard-and-fast rules regarding an upper limit on primer degenera- cy, and the success of any primer pair must be empirically determined. Innumerable failures have occurred when the primers were either incorrect "guessmers", yielding no products, or too degenerate, giving rise to a multitude of confusing, nonspecific products. One solution to this problem is to design more than one set of degenerate primers to the same site, thereby keeping substitutions to a minimum in each primer pool. Another solution is to substitute inosine for $\mathrm{N}$, for its ability to base pair with any nucleotide.

Improvements in the cycling parameters have received less attention, but a few methods, such as hot start PCR (4), have achieved wide acceptance. PCR optimization typically involves titration of template, primer, dNTPs, Taq DNA polymerase, and various buffer additives. The choice of optimum annealing temperature is particularly important. In conventional PCR, an annealing temperature of $5^{\circ} \mathrm{C}$ less than the predicted melting temperature of the primers is generally recommended. This advice is often inadequate for degenerate primers, which contain a mixture of primer sequences with highly variable annealing optima.

The hallmark of touchdown PCR $(6,7)$ is that the annealing temperature is lowered $1^{\circ} \mathrm{C}$ every two cycles, thereby allowing the most specific PCR products to gain a head start over nonspecific amplification products. Stepdown PCR (7) simplifies this program somewhat by lowering the annealing temperature in fewer but sharper increments. We have modified these approaches further in what we call ramped annealing PCR (RAN-PCR) in which the annealing temperature is gradually reduced within each PCR cycle. This modification led to the successful amplification of heat shock protein (Hsp90) genes from nematode genomic DNA using degenerate primers and may be generally applicable for degenerate PCR on com plex, uncharacterized templates.

Nematode genomic DNA was prepared according to Bird and Riddle (3). Genomic DNA from the pine wood nematode (Bursaphelenchus xylophilus) was the generous gift of Robert I. Bolla (St. Louis University, St. Louis, MO, USA). Genomic DNA extracts were prepared from single adult lesion nema- todes by the method of Thomas et al. (11). PCRs were conducted in $20-\mu \mathrm{L}$ total volume and contained $10 \mathrm{mM}$ Tris$\mathrm{HCl}, \mathrm{pH} 8.3,50 \mathrm{mM} \mathrm{KCl}, 3 \mathrm{mM}$ $\mathrm{MgCl}_{2}, 0.1 \%$ Triton ${ }^{\circledR} \mathrm{X}-100,0.005 \%$ gelatine, $200 \mu \mathrm{M}$ dNTPs, $25 \mathrm{ng}$ genom ic DNA, 1 U DisplayTAQ ${ }^{\mathrm{M}}$ (PGC Scientific, Gaithersburg, MD, USA), and $0.5 \mu \mathrm{M}$ each primer, U831 [5'-AA(T/C) $\mathrm{AA}(\mathrm{A} / \mathrm{G}) \mathrm{AC}(\mathrm{A} / \mathrm{C}) \mathrm{AAGCC}(\mathrm{A} / \mathrm{C} /$ G/T)T(T/C)TGGAC-3'] and L1110 [5'TC(A/G)CA(A/G)TT(G/A/C)TCCATGAT(A/G)AA(G/A/C) AC-3']. Primers were synthesized by Sigma-Genosys (Woodlands, TX, USA). Degeneracy is 64-fold for U831 and 72-fold for L1110. Primers were evaluated for duplex and hairpin formation using Oligo $^{\mathrm{TM}}$ Version 4 (Molecular Biology Insights, Cascade, CO, USA) (9). Hot-start reactions were assembled as follows: 10× DisplayTAQ buffer, $\mathrm{MgCl}_{2}$, dNTPs, primers, and water were combined in the bottom of a microcentrifuge tube and topped with a drop $(30-50 \mu \mathrm{L})$ of melted paraffin wax (Walnut Hill, Bristol, PA, USA). After the wax cooled, forming an even barrier, a top layer of additional buffer, water, template, and Taq DNA polymerase was added. RAN-PCR consisted of a prelim inary denaturation step at $94^{\circ} \mathrm{C}$ for 2 min, followed by 35 cycles at $94^{\circ} \mathrm{C}$ for $20 \mathrm{~s}, 65^{\circ} \mathrm{C}$ for $20 \mathrm{~s}, 60^{\circ} \mathrm{C}$ for $5 \mathrm{~s}, 55^{\circ} \mathrm{C}$ for $5 \mathrm{~s}, 50^{\circ} \mathrm{C}$ for $5 \mathrm{~s}, 45^{\circ} \mathrm{C}$ for $15 \mathrm{~s}$, and extension at $72^{\circ} \mathrm{C}$ for $1 \mathrm{~min}$, ending with a 5-min final extension at $72^{\circ} \mathrm{C}$. RANPCRs were conducted in $0.5-\mathrm{mL}$ thin wall microcentrifuge tubes in a PTC$130^{\mathrm{TM}}$ with the Hot Bonnet attachment (MJ Research, Watertown, MA, USA).

Degenerate primers were designed based largely on the known Caenorhabidits elegans Hsp90 sequence and both gradient PCR and touchdown PCR amplified specific Hsp90 products from C. elegans DNA (not shown). However, attempts to use the same conditions to amplify Hsp90 using DNA from our "test" plant parasite, the soybean cyst nematode, were unsuccessful (not shown). This led us to develop our modification of the touchdown procedure, RAN-PCR. In this method, annealing temperature is gradually reduced within each amplification cycle rather than between cycles. The initial annealing tem perature was set at $65^{\circ} \mathrm{C}$, a condition that favors reaction specificity. The tem perature was reduced in $5^{\circ} \mathrm{C}$ increments 
and then held for several seconds at $45^{\circ} \mathrm{C}$, a condition that may allow nonspecific priming but favors product yield. RAN-PCR led to specific amplification of Hsp90 sequences using genomic DNA from C. elegans, soybean cyst nematode, pine wood nematode, root-knot nematodes, and lesion nematode (Figure 1). In most cases, a single prominent band was produced. PCR products were cloned without further purification, using the $\mathrm{TOPO}^{\mathrm{M}} \mathrm{TA}$ Cloning kit (Invitrogen, Carlsbad, CA, USA) and sequenced using M13 forward and reverse primers. BLASTX analysis (1) confirmed that the sequences generated by this PCR were genuine members of the Hsp90 gene family. Slight differences in the size of amplified fragments reflect differences in number and length of introns within the amplified regions. Specific products were also produced when crude genom ic DNA extracts from single-lesion nematodes were used as template (Figure 1). Thus, RAN-PCR annealing conditions successfully accommodated moderate primer degeneracy (64-fold for U831 and 72-fold for L1110) and variable template quality, yet maintained the reaction specificity and yielded am ple product for cloning.

In any PCR, amplification begins when the melting temperature $\left(\mathrm{T}_{\mathrm{m}}\right)$ of the specific primer-template combination is reached. Calculation of primer $\mathrm{T}_{\mathrm{m}}$ is the standard for estimating the optimal annealing temperature to use for PCR. However, the commonly used formulas for calculating $\mathrm{T}_{\mathrm{m}}$ do not take into account the multiple nucleotide choices found in degenerate primers. The U831 and L1110 primer pools contain individual primers that vary in melting temperature by as much as $22^{\circ} \mathrm{C}$, depending on the method used to calculate $T_{m}$ (2). This is consistent with the findings of Hecker and Roux (7), who showed that the melting temperatures of degenerate and even nondegenerate primers could vary by as much as $27^{\circ} \mathrm{C}$. Considering the obvious limitations of mathematical estimations of primer $\mathrm{T}_{\mathrm{m}}$, it is not surprising that PCR using fixed annealing temperatures failed to generate the correct $\mathrm{Hsp} 90 \mathrm{am}$ plification products. The failure of touchdown PCR is less clear because this procedure is designed to accommodate suboptimal reaction conditions. It is possible that every cycle in RANPCR was productive, whereas, in touchdown PCR, only the later cycles were productive but did not produce enough product to be seen on a gel. We found that RAN-PCR eliminated the need for repetitive, time-consuming, and expensive optimization of degenerate PCR

conditions and allowed template DNA of variable quality to be examined under the same conditions. Programming RAN-PCR is relatively easy and does not consume large amounts of file space on most thermocyclers. RAN-PCR provides another alternative to touchdown and stepdown PCR and may be broadly applicable in degenerate or multiplex PCR when other methods have failed to produce the desired PCR products. It may also provide a flexible starting point for PCR optimization of uncharacterized DNA templates.

\section{REFERENCES}

1.Altschul, S.F., W. Gish, W. Miller, E.W. Myers, and D.J. Lipman. 1990. Basic local alignment search tool. J. Mol. Biol. 215:403410.

2.Baldino, F., Jr., M.-F. Chesselet, and M.E. Lewis. 1989. High-resolution in situ hybridization histochemistry. Methods Enzymol. 168:761-777.

3.Bird, D.M. and D.L. Riddle. 1989. Molecular cloning and sequence of ama-1, the gene encoding the largest subunit of Caenorhabidits elegans RNA polymerase II. Mol. Cell. Biol. 9:4119-4130.

4.Chou, Q., M. Russell, D.E. Birch, J. Raymond, and W. Bloch. 1992. Prevention of pre-PCR mis-priming and primer dimerization improves low-copy-number amplifications. Nucleic Acids Res. 20:1717-1723.

5.Dieffenbach, C.W, T.M. Lowe, and G.S. Dveksler. 1993. General concepts for primer design. PCR Methods Appl. 3:S30-S37.

6.Don, R.H., P.T. Cox, B.J. Wainwright, K. Baker, and J.S. Mattick. 1991. "Touchdown" PCR to circumvent spurious priming during gene amplification. Nucleic Acids Res. 19:4008.

7.Hecker, K.H. and K.H. Roux. 1996. High and low annealing temperatures increase both specificity and yield in touchdown and stepdown PCR. BioTechniques 20:478-485.

8.Rychlik, W. 1995. Selection of primers for polymerase chain reaction. Mol. Biotechnol. 3:129-134.

9.Rychlik, W. and R.E. Rhoads. 1989. A com puter program for choosing optimal oligonucleotides for filter hybridization, sequencing and in vitro amplification of DNA. Nucleic Acids Res. 17:8543-8551.

10.Singh, V.K., A.K Mangalam, S. Dwivedi, and S. Naik. 1998. Primer premier: program for design of degenerate primers from a protein sequence. BioTechniques 24:318-319.

11.Thomas, W.K., J.T. Vida, L.M. Frisse, M. Mundo, and J.G. Baldwin. 1997. DNA sequences from formalin-fixed nematodes: integrating molecular and morphological approaches to taxonomy. J. Nematol. 29:250-254.

Figure 1. RAN-PCR amplification of Hsp90 genes from nematodes. $M=100$-bp ladder (New England Biolabs, Beverly, MA, USA) (1500, 1200, 900, 800, 700, 600, 500, 400, 300, 200, 100); Hg = Heterodera glycines (soybean cist nematode); $\mathrm{Ce}=C$. elegans; $\mathrm{Ma}=$ Meloidogyne arenaria $; \mathrm{Mj}=M$. javanica (root-knot nematode); $\mathrm{Bx}=$ B. xylophilus (pine wood nematode); $\mathrm{Pz}=$ Pratylenchus zeae (lesion nematode). Fifteen microliters out of $20-\mu \mathrm{L}$ PCRs were examined on $1 \%$ SeaKem ${ }^{\circledR}$ GT G $^{\circledR}$ agarose (BMA, Rockland, ME, USA) in $1 \times$ TAE.

12.Thompson, J.D., D.G. Higgins, and T.J. Gibson. 1994. CLUSTAL W: improving the sensitivity of progressive multiple sequence alignment through sequence weighting, posi- 
tion-specific gap penalties and weight matrix choice. Nucleic Acids Res. 22:4673-4680.

The authors would like to thank Sonja Scheffer for help with DNA sequencing and Roberta Henegar, Sharon Ochs, Nicole Guimond, and Patrice Armstrong for excellent technical assistance. Mention of a trade name or commercial product in this publication is solely for the purpose of providing specific information and does not imply recommendation or endorsement by the U.S. Department of Agriculture. Address correspondence to Dr. Andrea M. Skantar, USDA-ARS Nematology Lab, Bldg. 011-A BARC West, Rm. 130, Beltsville, MD 20705 , USA.e-mail: skantara@ba.ars.usda.gov

Received 12 May 2000; accepted 1 September 2000.

\section{Andrea M. Skantar and Lynn K. Carta}

US Department of AgricultureARS Nematology Lab

Beltsville, MD, USA

\section{Fluorescent Multiplex PCR and Capillary Electrophoresis for Analysis of PKD1 and PKD2 Associated Microsatellite Markers}

BioTechniques 29:1186-1190 (December 2000)

Autosomal dominant polycystic kidney disease (ADPKD) is one of the most common genetic disorders in man, with an incidence of 1 in 1000. It is characterized by progressive renal cystic disease typically leading to end stage renal disease (ESRD) in the sixth decade (4). There are at least two ADP$\mathrm{KD}$ loci responsible for the disease: PKD1 on 16p13.3 and PKD2 on 4q21q23 $(7,10,16)$. However, there are also evidences of a third PKD locus (2). To perform mutation screening, the gene involved in the progression of the disease in a particular family must first be assigned by genetic linkage analysis. Analysis of PKD1 and PKD2 gene associated microsatellite markers is therefore crucial before performing mutation search in these families. In ADPKD linkage studies described to date, only classical polyacrylamide gel electrophoresis approaches were used to assess the lengths of the amplified al- leles (References 1, 9, 12 and others). We developed three fluorescent multiplex PCRs for optimized simultaneous amplification of nine highly polymorphic PKD1 and PKD2 associated microsatellites: D16S291 (13); D16S664, D16S665, and D16S663 (9); D16S3252 (12); D4S423, D4S1534, D4S1563, and D4S2929 (3) (Figure 1). To get a better resolution and to reduce manual work, we used capillary electrophoresis instead of polyacrylamide electrophoresis to assess the lengths of amplified products. Due to different electrophoretic mobility of complementary strands of the amplified product, CA strands move faster on the denaturating polyacrylamide gels than GT strands (11). This can result in two bands instead of one for the same allele. In the case of capillary electrophoresis, only one of the strands is fluorescently labeled; therefore, only one can be visualized (6).

Genomic DNA was extracted from white blood cells by a standard salting out procedure (8) or from blood spots by a Chelex ${ }^{\circledR} 100$ (Bio-Rad Laboratories, Hercules, CA, USA) based protocol (15). We used previously published primer pairs (http://www.gdb.org). One of the primers from each pair was endlabeled with a distinct fluorescent dye (Table 1). Multiplex PCRs were performed on a GeneAmp ${ }^{\circledR}$ PCR System 9600 thermal cycler (Applied Biosys-

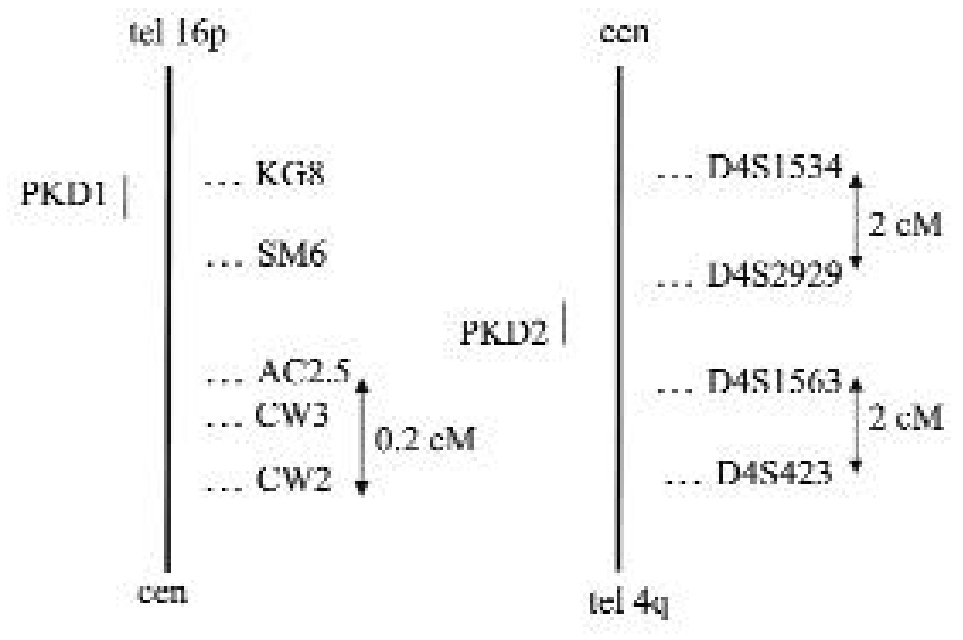

Figure 1. Map of the microsatellite markers around PKD1 (16p13.3) and PKD2 (4q21-q23) genes. Data are summarized from various sources $(1,5,9,12)$. Approximate genetic distances are given in centiMorgans (cM). 